\title{
Levantamento de dados em pro- priedades leiteiras para sucessão familiar no Vale do Taquari
}

\section{Sedenir Dahm}

Ricardo Fleck

Fernanda Leal Leães

Bruna Klein

Voltaire Sant'Anna
Universidade Estadual do Rio Grande do Sul, Campus em Encantado, Encantado, Rio Grande do Sul, Brasil

E-mails: sedenirdahm@gmail.com ricardo_fleck@yahoo.com fernanda-leaes@uergs.edu.br bruna-klein@uergs.edu.br voltaire-santanna@uergs.edu.br

Recebido em: 17 mar. 2017. Revisado em: 21 mar. 2017. Aceito: 02 abr. 2017.

DOI: http://dx.doi.org/10.21674/2448-0479.34.723-731

\section{Resumo}

Por ser uma atividade desenvolvida no meio rural, a sucessão familiar das propriedades que produzem leite é uma questão de grande importância, uma vez que se observa um expressivo êxodo rural, principalmente em municípios do interior. Poucas informações são encontradas na literatura sobre o perfil dos proprietários de empreendimentos que produzem leite no Vale do Taquari, sendo a questão da sucessão familiar nestas propriedades ainda menos explorada. O presente trabalho tem como objetivo avaliar a atual situação dos produtores na área de bovinocultura leiteira, realizando um diagnóstico da sucessão familiar em propriedades rurais no Vale do Taquari. Para 
isso, foram realizadas entrevistas com 10 proprietários em de três microrregiões Vale do Taquari, com perguntas enfocando a percepção deles em relação a viabilidade do tambo para os próximos anos. Os resultados mostram que os proprietários apresentam renda alternativa à produção de leite. A maior parte dos tambos têm entre $50 \mathrm{e}$ 100 cabeças na propriedade, sendo consideradas de médio porte, tendo em vista as características regionais. Percebe-se também que, no quesito acessibilidade há alguns casos pontuais onde o acesso é mais difícil. Os resultados também indicam que, tanto para os atuais gestores quanto para os sucessores, estão conscientes de que um tambo leiteiro pode ser bastante rentável, e também tem interesse em permanecer na propriedade, deste que tenha uma gestão adequada e controlada. Assim, é importante ressaltar a importância da manutenção e expansão de ações e de políticas públicas que promovam o incentivo à permanência do jovem no meio rural, promovendo assim o desenvolvimento rural da região.

Palavras-chave: Produção de Leite. Êxodo rural. Desenvolvimento rural.

\section{Introdução}

A cadeia produtiva de leite vem sofrendo diversas alterações para atender o mercado consumidor, principalmente no que tange $o$ seu beneficiamento. As grandes indústrias têm tratado de ampliar suas escalas de produção com aquisição de outras empresas, além de investir em modernização em seus parques industriais, e no lançamento de novos produtos afim de atender mercados nacionais e 
internacionais. Com este cenário de ambiente competitivo, se intensificam as exigências aos produtores de leite, tanto quanto na quantidade como também na qualidade da matéria prima (FLORES et al., 2006).

Apesar de muitos dos bovinocultores leiteiros acompanharem as mudanças, muitos produtores familiares, diante deste novo cenário, se veem incapacitados de atender exigências de um mercado de grandes empresas como: produção em escala, mão de obra mais especializada, escassez de terras, rebanho desuniformes. Outro grande desafio para as propriedades rurais é quebrar velhos hábitos e restrições aos avanços da cadeia produtiva de leite, a qual cada vez mais busca a automatização da produção, maior eficiência produtiva, higienização entre outros (CARVALHO, 2016). Neste contexto, observa-se a intensificação do êxodo rural em municípios do interior do Brasil, acarretando em grandes entraves para a fixação de jovens no campo, principalmente na sucessão familiar nas propriedades rurais. Estes fatores têm alavancado a preocupação com o desenvolvimento regional sustentável em âmbito regional e nacional (FONTES et al.; 1998; ÁVILA et al., 2003).

Ao contrário das demais regiões, onde a produção de leite é uma atividade complementar a outras atividades da propriedade rural, o Vale do Taquari, juntamente com a região norte do Estado do Rio Grande do Sul, tem como característica a produção de leite como a principal atividade de renda. Porém, poucos trabalhos ainda lidam com a caracterização e diagnóstico dessas propriedades rurais, dados esses de extrema importância para a promoção de políticas públicas que beneficiem os trabalhadores dessa importante cadeia agroalimentar do país.

Assim, o presente projeto objetiva realizar um estudo sobre a cadeia produtiva do leite do Vale do Taquari, enfocando na suces- 
são familiar nessas propriedades, com a finalidade de gerar um diagnóstico do atual cenário no Vale do Taquari.

\section{Metodologia}

Foram realizadas visitas às propriedades agrícolas, que possuem como principal atividade a produção de leite, nos municípios de Encantado, Vespasiano Correa, Arroio do Meio, Estrela e Teutônia. Para obter os dados, foi elaborado um formulário de entrevista com 19 questões objetivas e 1 subjetiva, com a finalidade de conhecer a atual situação dos produtores, seu perfil pessoal e da propriedade, enfocando no processo de sucessão familiar que o entrevistado estava perfazendo.

Foram realizadas entrevistas a 10 propriedades, escolhidas de forma aleatória, no período 04 a 30 de abril de 2016. Também foi questionado se nas propriedades existe alguma atividade complementar. Tendo os dados apurados, compilou-se em planilhas e gráficos, em Excel. Os dados foram analisados levando em conta a ordem de importância que mais foi apontada pelos entrevistados, em seguida analisou-se brevemente as respostas.

\section{Resultados e discussão}

Os resultados mostram que $10 \%$ dos entrevistados, $(n=1)$ possuem ente 30 a 50 animais na propriedade, $50 \%$ tem menos de 100 cabeças $(n=5), 30 \%$ dos entrevistados possuem mais de 100 cabeças e $10 \%(n=1)$ tem mais de 200 animais em suas propriedades. Sendo as mesmas de raça holandesa, que possui como caracRev. Elet. Cient. UERGS, v. 3, n. 4 (Número Especial), p. 723-731, 2017. 
terística a produção de leite e mais resistentes ao frio, que é característico da região durante grande parte do ano. Dados similares foram observados por Cyrne (2015), que também caracterizou desta forma um perfil de pequenas propriedades no Vale do Taquari, constatando que a maioria das propriedades possuem fonte de renda alternativa. Informação que também é salientada pelo caderno da assessoria de imprensa da Emater RS que afirma a diversificação produtiva dos agricultores familiares como garantia de sucessão na família (EMATER, 2015).

Os resultados demonstram que $30 \%(n=3)$ dos entrevistados não tem nenhuma fonte de renda alternativa, enquanto que $70 \%$ $(n=7)$ já estão com outras fontes de renda alternativa além da produção leiteira, entre as principias, a criação de suínos, aves e grãos, formando um modelo de gestão baseado na diversificação da propriedade. Isso é muito importante principalmente para os locais onde o planejamento é menos eficiente, pois assim, quando tiverem alguma dificuldade no setor poderão contar com a fonte alternativa.

As entrevistas apontam que $10 \%(n=1)$ dos entrevistados consideram que sua estrutura é um ponto favorável na produção de leite, $30 \%(n=3)$ indicam que a localização é o diferencial no elo produtivo, $40 \%(n=4)$ acham que a qualidade do leite é o ponto forte de sua propriedade e $30 \%(n=3)$ diz que a genética de seu plantel é o seu principal ponto positivo.

Pode-se perceber, que o proprietário tem preocupação com a localização de seu estabelecimento, o que é um ponto muito importante para a gestão do tambo, pois sendo ela bem localizada, facilita a distribuição bem como no fornecimento de insumos, barateando os custos de produção. Outro quesito importante, é a qualidade do leite oferecido, pois com um produto de boa qualidade, pode-se conseguir preços melhores por parte dos laticínios. E em seguida, 
observa-se a genética como ponto positivo, que vem ao encontro da produção, pois sabe-se que a quantidade de leite produzido por animal, depende muito das condições do mesmo.

Também, observou-se que $10 \%(n=1)$ das propriedades tem como principal dificuldade o pouco espaço para a ampliação de seu plantel, $20 \%(n=2)$, consideram a localização como um ponto negativo, $10 \%(n=1)$ tem pouca estrutura em sua propriedade e $60 \%(n=6)$ tem problemas com a mão de obra. O principal ponto apontado pelos proprietários de tambos, foi a falta de mão de obra. Problema este que também acomete a área urbana atualmente, porém de forma menos complexa, uma vez que na propriedade rural os horários são muito mais extensos, o comprometimento é indispensável e a especialização do serviço se torna importante para obter os resultados, que dependem diretamente da mão de obra prestada.

Sobre o perfil etário dos proprietários. $10 \%(n=1)$ dos proprietários entrevistados apresentam idade entre 20 e 35 anos, $50 \%$ $(n=5)$ de 36 a 45 anos, 30\% (n=3) entre 46 e 55 anos e $30 \%(n=3)$ mais que 56 anos. Esses números se mantem correspondidos aos dados levantados por Cyrne (2015). DIESSE (2010), também apontou o envelhecimento dos atuais proprietários de tambos leiteiros.

Observa-se ainda no presente trabalho que atualmente há parte de produtores com idade entre 36 e 45 anos, sendo que na maioria dos casos já passaram pelo processo de sucessão, mostrando que os dados levantados por Cyrne (2015), estão corretos quando diz que $40 \%$ das propriedades provem de heranças. Estas propriedades eram conduzidas pelos seus pais, que decidiram mandar seus filhos estudando para que ficassem aptos a administrar os negócios. Os dados mostram uma evolução àquilo observado por Silvestro (2001), que observou pouca organização na gestão da propriedade rural. Estes atuais donos, por sua vez, já estão pensan- 
do em ensinar a próxima geração para que o negócio familiar se mantenha. Percebe-se que vários tem interesse em passar a gestão dos negócios para seus filhos e muitos já estão preparando o próximo sucessor como mostra a tabela 6 abaixo:

Os dados indicam que $30 \%(n=3)$ não fez nenhum planejamento de sucessão, $10 \%(n=1)$ já pensou em fazer, $50 \%(n=5)$ está em processo de sucessão e $10 \%(n=1)$ já concluiu a sucessão da propriedade leiteira.

Entre os dez entrevistados, quatro ainda não pensaram em fazer o planejamento, porque seus filhos são menores de dezesseis anos. Contudo, nesses também existe o interesse de passar a propriedade e a gestão dos negócios para seus filhos. Percebe-se que no Vale do Taquari, já existe um perfil determinado onde os ensinamentos são passados de pai para filho. Em entrevista realizada nas propriedades, das 10 amostras coletadas, 4 afirmaram que estão ensinando os sucessores na gestão dos negócios, e entre os entrevistados, em 3 propriedades já são os sucessores que estão gerenciando a propriedade.

O ponto em que chama a atenção no gráfico anterior, é que entre os entrevistados não constou pessoas que estão buscando se especializar na área da gestão agrícola, alguns até fazem algum tipo de curso superior, porém não chega ser algo especifico da atividade.

\section{Conclusão}

Assim, observa-se que as propriedades leiteiras estudadas apresentam em média mais de 100 cabeças de gado para a produção de leite, sendo que seus proprietários estão buscando fontes alternativas de renda para tornar a propriedade mais rentável. Os 
dados mostram que os proprietários de fazendas leiteiras no Vale do Taquari estão envelhecendo e a sucessão familiar nesses locais se torna um ponto de política pública crucial para a região, questão ainda pouco tratada pelos entrevistados. Os dados apresentados indicam a necessidade de ações junto às comunidades rurais do Vale do Taquari principalmente no que tange a sucessão familiar nas propriedades, visando a manutenção da atividade leiteira na região.

\section{Referências}

AVILA, M.; AVILA, S.S.A.; FERREIRA, C.J. Administração Rural: elementos de estudo na Fazenda Corrégo da Liberdade no município de Ipiranga de Goiás. Revista Eletrônica de Ciência Administrativa, Campo Largo v 1 n3 nov 2003. Disponível em: http://revista.facela.com.br. Acesso em 11 de abril de 2016.

CARVALHO, M.P. Impasse tecnológico, Milk Point, 2001. Disponível em: http://www.milkpoint.com.br/cadeiadoleite/editorial/impassetcnologic o-8304n.aspx. Acesso em 15/04/16.

CYRNE. C.C.S. Indicadores de gestão em propriedades produtoras de leite do Vale do Taquari/RS - Um estudo comparativo com as propriedades da Região da Galícia- Espanha. (Tese de doutorado em Ambiente e Desenvolvimento) - Programa de PósGraduação. Centro Universitário UNIVATES, Lajeado 2015.

DIEESE, Elaboração de instrumentos de monitoramento e analise para a gestão política de arranjos produtivos locais do Rio Grande do Sul, 2014.

EMATER, Relatório socioeconômico da cadeia produtiva do leite no Rio Grande do Sul, Porto Alegre, 2015. 
FLORES, A.W. et al. Gestão Rural. Porto Alegre: Ed. dos Autores, 2006. 328 p.

FONTE, L.M.. et al Estudo da cadeia produtiva do leite do estado do Rio Grande do Sul n 3 Porto Alegre, 1998.

SILVESTRO, M.L. et. al Os impasses sociais da sucessão hereditária na agricultura familiar, Florianópolis, Ed Epagri 2001, 102 p. 